\title{
DEGREE OF RISK RELATED TO PROCEDURES PERFORMED IN CONJUNCTION WITH SURGICAL MYOCARDIAL REVASCULARIZATION IN OCTOGENARIANS
}

\author{
Jose Carlos Rossini Iglezias, Luis Alberto Oliveira Dallan, Artur Lourenção Jr., \\ Alex Luiz Celullare, Raiane Pereira, Noedir Antonio Groppo Stolf
}

doi: $10.1590 / \mathrm{S} 1807-59322009000500003$

\begin{abstract}
Iglezias JCR, Dallan LAO, Lourenção Jr. A, Celullare AL, Pereira R, Stolf NAG. Degree of risk related to procedures performed in conjunction with surgical myocardial revascularization in octogenarians. Clinics. 2009;64(5):387-92.
\end{abstract}

INTRODUCTION/OBJECTIVES: We determined the degree of risk produced by the association of other surgical procedures with surgical myocardial revascularization in octogenarian patients and identified the risk factors that best explain hospital mortality. METHODS: This study was an observational analytical historical cohort study involving octogenarians operated on at our institution between January 1, 2000 and January 1, 2005. We stratified the objective population as follows: Group 1 comprised octogenarians revascularized without associated procedures, and Group 2 comprised octogenarians revascularized with associated procedures. Statistical analyses included the $t$ test for independent samples and multiple logistic regression analysis. Significance was accepted with an alpha error of $5 \%$.

RESULTS: Univariate analyses revealed the following clinical and statistically significant variables: hospital mortality ( $\mathrm{P}=0.002)$, diabetes mellitus $(\mathrm{P}=0.017)$, preoperative endocarditis $(\mathrm{P}=0.001)$, cardiogenic shock $(\mathrm{P}=0.019)$, use of an intra-aortic balloon pump $(\mathrm{P}=0.026)$, preoperative risk score (Parsonnet), $\mathrm{P}<0.001$, procedure associated with revascularization $(\mathrm{P}<0.001)$, medium number of affected coronary arteries $(\mathrm{P}<0.001)$, use of extracorporeal circulation $(\mathrm{P}<0.001)$, time of extracorporeal circulation $(\mathrm{P}<0.001)$, number of distal anastomoses $(\mathrm{P}=0.002)$, graft type $(\mathrm{P}<0.001)$, postoperative breathing support $(\mathrm{P}<0.001)$, stroke $(\mathrm{P}<0.001)$, infection $(\mathrm{P}=0.002)$, creatinine level $(\mathrm{P}=0.018)$, and quality of life score $(\mathrm{P}=0.050)$.

DISCUSSION/CONCLUSIONS: In octogenarian patients, the need for a procedure associated with surgical myocardial revascularization produces an absolute increase in hospital mortality risk of $45 \%$. The variables that contributed to hospital mortality were preoperative endocarditis, preoperative cardiogenic shock, the use of extracorporeal circulation, the length of time of extracorporeal circulation, postoperative creatinine level, and postoperative need for prolonged respiratory support.

KEYWORDS: Myocardial revascularization; Coronary artery bypass; Aged, 80 and over; Coronary artery bypass, Off pump; Aged groups.

\section{INTRODUCTION}

Jones et al. ${ }^{1}$ analyzed 799 patients undergoing primary elective aortic valve replacement associated with myocardial revascularization between March 1986 and May 2000, and affirmed that the treatment of coronary artery disease

Cirurgia Cardíaca, INCOR, Hospital das Clinicas da Faculdade de Medicina da Universidade de São Paulo - São Paulo/SP, Brazil.

Email: dcirossini@incor.usp.br

Tel.: 55113069.5014

Received for publication on November 19, 2008

Accepted for publication on February 03, 2009 combined with aortic valve replacement improves clinical outcomes; however, when survival was compared with isolated valve replacement, the outcome remained uncertain, as did the use of the left thoracic internal mammary artery (LIMA) graft for the left anterior descending (LAD) branch. Multiple regression analyses identified the following as independent predictors of decreased survival: advanced age $(\mathrm{P}<0.001)$, female sex $(\mathrm{P}<0.001)$, absence of diabetes $(\mathrm{P}=0.02)$, the number of grafts in the operation $(\mathrm{P}=0.04)$, absence of congenital valve disease $(\mathrm{P}=0.001)$, and valve insufficiency $(\mathrm{P}=0.008)$. The effect of the LIMA-LAD coronary graft was not significant based on multivariate analyses. 
Nwakanma et al. ${ }^{2}$ concluded that combined surgical treatment for carotid arteries and myocardial revascularization does not increase mortality and morbidity in short- and long-term follow-up when compared with isolated revascularization. The late follow-up data included myocardial infarction, stroke, and death. No statistical differences were noted between groups regarding the outcomes of death, stroke, and myocardial infarction in the 60-month follow-up ( $\mathrm{P}>0.05)$.

Woo et al. ${ }^{3}$ reported that left ventricular dysfunction is an independent predictor of morbidity and hospital mortality in myocardial revascularization accomplished with the aid of extracorporeal circulation, and that completing the procedure without extracorporeal circulation support represents an effective and safe way to treat patients with significant left ventricular dysfunction.

Sirivella ${ }^{4}$ et al. analyzed 468 patients who underwent concomitant mitral valve and coronary artery surgeries and identified the following as predictors of hospital mortality: severe coronary disease, prior acute myocardial infarction, low ejection fraction, ischemic mitral insufficiency, symptoms of advanced heart failure, not using the internal thoracic artery, valve substitution, and emergency surgery.

Jensen et al. ${ }^{5}$ studied the quality of life related to revascularization with and without extracorporeal circulation in seniors with moderate- and high-operative risk, and reported that quality of life improved in both groups after the operation; significant clinical differences did not exist between the groups. One exception was improved problem solving in patients operated on with the aid of extracorporeal circulation $(\mathrm{P}=0.04)$.

Onorati et al. ${ }^{6}$ analyzed 50 patients with chronic obstructive pulmonary disease (COPD) stratified into two groups of 25 in order to test the effects of the intraaortic balloon on the preservation of lung function. It was concluded that the use of the intra-aortic balloon at an automated regimen of 80 beats per minute during cardiac arrest induced by a cardioplegic solution preserved lung function in patients with COPD.

Biancari et al. ${ }^{7}$ evaluated the predictive value of EuroSCORE for identification of patients at high risk for adverse clinical outcomes after heart surgery. It was concluded that EuroSCORE represents a relevant predictor for immediate and late outcomes after myocardial revascularization with extracorporeal circulation.

Reddy et $a .^{8}$ examined the effect of extracorporeal circulation on patients' breathing. It was concluded that surgery without extracorporeal circulation offers benefits to patients with a high respiratory risk by reducing the time of postoperative breathing support, and that patients operated on without extracorporeal circulation also had smaller alveolus-arterial gradients in the immediate postoperative period; however, that last result did not reach statistical significance. We ourselves have examined results of elective vs non-elective radial artery grafts. ${ }^{9}$

Rankin et al. ${ }^{10}$ evaluated the risk factors for hospital mortality in the surgical treatment of valvulopathy. The relevance of the risk factors was based on odds ratios. The factors with the greatest significance were non-elective surgery $(\mathrm{OR}=2.11)$, advanced age $(\geq 70$ years) $(\mathrm{OR}=1.88)$, re-operation $(\mathrm{OR}=1.61)$, endocarditis $(\mathrm{OR}=1.59)$, and coronary artery disease $(\mathrm{OR}=1.58)$. Valve substitution compared with valvuloplasty was found to be associated with the greatest mortality $(\mathrm{OR}=1.52)$. In general, improved clinical outcomes were less prevalent in females $(\mathrm{OR}=1.34)$ during the study period. However, any isolated comorbidity, on average, made a moderate contribution to the risk $(\mathrm{OR}=1.19)$. Specific comorbidities such as renal insufficiency or multiple comorbidities in certain patients could have significant effects. Reconstruction of the aortic arch had the highest risk $(\mathrm{OR}=2.78)$ followed by tricuspid valve $(\mathrm{OR}=2.26)$, multiple valve $(\mathrm{OR}=2.06)$, isolated valve $(\mathrm{OR}=1.47)$, pulmonary valve $(\mathrm{OR}=1.29)$, and aortic valve procedures. The degree of reduction in the ejection fraction and the severity of the valvular lesion were relatively less important ( $\mathrm{OR}=1.34$ and 0.83 , respectively).

Our study was conducted to identify the risk factors for hospital mortality in octogenarian patients who underwent procedures associated with surgical myocardial revascularization. We also sought to determine the degree of risk produced by the association of other surgical procedures with surgical myocardial revascularization in these patients.

\section{MATERIALS AND METHODS}

This was an observational, analytical study of the historical cohort type involving patients operated on at our hospital from January 1, 2000 to January 1, 2005. We stratified the objective population into the following study samples: Group 1 (G1) comprised octogenarian patients revascularized without associated procedures, and Group 2 (G2) comprised octogenarians revascularized with one or more associated procedure. Statistical analyses included the $t$ test for independent samples followed by multiple logistic regression analysis for better adjustment of the model and explanation of hospital mortality. Significance was accepted for an alpha error of 5\%.

\section{RESULTS}

Univariate analysis was performed on 53 parameters 
(Table 1) comparing Group 1 with Group 2 (Table 2). Although some differences were found in the parameters between Groups 1 and 2, not all of these differences were statistically significant. Patients included 45 (39.13\%) females and $70(60.86 \%)$ males in Group 1 and $15(46.87 \%)$ females and $17(53.12 \%)$ males in Group $2(\mathrm{P}=0.456)$. Group 1 patients were $82.59 \pm 2.05$ years of age, and Group 2 patients were $83.40 \pm 2.63$ years of age $(\mathrm{P}=0.065)$. The hospital stay in $\mathrm{G} 1$ was $16.10 \pm 15.98$ days versus $18.59 \pm 19.77$ in $\mathrm{G} 2(\mathrm{P}=0.461)$.

Diabetes was less prevalent in Group 2 patients undergoing associated procedures $(12.5 \%$ versus $34.8 \%$, $\mathrm{P}=0.017$ ),

The intra-aortic balloon pump was used in a greater percentage of Group 2 patients undergoing associated procedures.

Cardiogenic shock was greater in the Group 2 patients undergoing associated procedures than in Group 1 patients (22.6\% versus $7.8 \%, \mathrm{P}=0.019$ ). Preoperative endocarditis was more prevalent in Group 2 than in Group 1 patients (15.6\% versus $1.7 \%, \mathrm{P}=0.001)$. All-cause hospital mortality was greater in Group 2.

We observed a larger number of arteries affected by coronary artery disease in Group 1 patients who did not undergo associated procedures $(2.59 \pm 0.67$ versus $2.06 \pm 0.71$, $\mathrm{P}<0.001)$.

Extracorporeal circulation was used in a greater percentage of Group 2 patients (100\% versus 57\%, $\mathrm{P}<0.001)$.

The time of extracorporeal circulation was longer in Group 2 patients $(122.37 \pm 35.12$ versus $52.37 \pm 52.78$, $\mathrm{P}<0.001)$ as was the clamp time for the aorta $(88.92 \pm 26.24$ versus $32.70 \pm 34.76, \mathrm{P}<0.001)$.

The number of distal grafts was smaller in Group 2 than in Group 1 patients $(2.08 \pm 0.80$ versus $2.57 \pm 0.89$, $\mathrm{P}=0.002$ ).

Considering the type of graft used, pure (vein only) or combined arterial grafts (only artery or artery and vein) were used in a greater number of Group 1 patients $(68.5 \%$ versus $23.3 \%, \mathrm{P}<0.001)$.

Parsonnet preoperative risk scores were higher in Group 2 than in Group 1 patients $(33 \pm 8.33$ versus $24.12 \pm 8.39$, $\mathrm{P}<0.001)$.

A larger percentage of Group 2 than Group 1 patients had elevated postoperative creatinine levels $(3.1 \%$ versus $1.7 \%, \mathrm{P}=0.018$ ).

Group 2 had the largest percentage of postoperative stroke (21.9\% versus $3.5 \%, \mathrm{P}<0.001)$.

The need for breathing support at 24 hours was greater in Group 2 than in Group 1 patients (53.12\% versus 19.1\%, $\mathrm{P}<0.001)$.
Table 1 - Characterization of the groups

\begin{tabular}{|c|c|c|c|}
\hline Variables & $\begin{array}{l}\text { G1 CABG with- } \\
\text { out AP }\end{array}$ & $\begin{array}{c}\text { G2 CABG with } \\
\text { AP }\end{array}$ & P Value \\
\hline $\mathrm{N}^{\mathrm{o}}$. of patients & 115 & 32 & \\
\hline Age & $82,59 \pm 2,18$ & $83,40 \pm 2,63$ & 0,513 \\
\hline Sex & & & 0,456 \\
\hline Male & $70(60,86 \%)$ & $17(53,12 \%)$ & \\
\hline Female & $45(39,13 \%)$ & $15(46,87 \%)$ & \\
\hline Weight & $68,40 \pm 10,56$ & $64,21 \pm 10,87$ & 0,066 \\
\hline Height & $1,62 \pm 0,08$ & $1,59 \pm 0,09$ & 0,193 \\
\hline Body mass index & $26,01 \pm 3,50$ & $25,07 \pm 3,28$ & 0,202 \\
\hline Diabetes & & & 0,017 \\
\hline No & $74(64,3 \%)$ & $27(84,4 \%)$ & \\
\hline Yes & $40(34,8 \%)$ & $4(12,5 \%)$ & \\
\hline Card. shock. preop. & & & 0,019 \\
\hline No & $106(97,2 \%)$ & $24(77,4 \%)$ & \\
\hline Yes & $9(2,8 \%)$ & $7(22,6 \%)$ & \\
\hline Int.aort.balloon préop. & & & 0,026 \\
\hline No & $108(93,9 \%)$ & $26(81,3 \%)$ & \\
\hline Yes & $7(6,1 \%)$ & $6(18,8 \%)$ & \\
\hline Preop. Endocarditis & & & 0,001 \\
\hline No & $113(98,3 \%)$ & $27(84.4 \%)$ & \\
\hline Yes & $2(1,7 \%)$ & $5(15,6 \%)$ & \\
\hline $\begin{array}{l}\text { Preop. score of risk } \\
\text { (Parsonnet) }\end{array}$ & $24,12 \pm 8,39$ & $33,00 \pm 8,33$ & 0,000 \\
\hline $\mathrm{N}^{\mathrm{o}}$. damaged arteries & $2,59 \pm 0,67$ & $2,06 \pm 0,71$ & 0,000 \\
\hline Extracorporeal use & & & 0,000 \\
\hline No & $66(57,39 \%)$ & $0,0(0,0 \%)$ & \\
\hline Yes & $49(42,6 \%)$ & $32(100 \%)$ & \\
\hline Time of extracorporeal & $52,37 \pm 52,78$ & $122,37 \pm 35,12$ & 0,000 \\
\hline Aortic clamping time & $32,70 \pm 34,76$ & $88,92 \pm 26,24$ & 0,000 \\
\hline $\mathrm{N}^{\mathrm{o}}$ distal anastomosis & $2,57 \pm 0,89$ & $2,0 \pm 0,80$ & 0,002 \\
\hline Graft type & & & 0,000 \\
\hline Arterial or mixed & $78(68,5 \%)$ & $8(23,3 \%)$ & \\
\hline Venuos & $37(31,5 \%)$ & $24(76,7 \%)$ & \\
\hline Breath supp. . $\geq 24 \mathrm{hs}$ & & & 0,000 \\
\hline No & $93(80,9 \%)$ & $15(46,87 \%)$ & \\
\hline Yes & $22(19,1 \%)$ & $17(53,12 \%)$ & \\
\hline Posop. creatinine & & & 0,018 \\
\hline No & $102(88,7 \%)$ & $23(71,9 \%)$ & \\
\hline Yes & $13(11,3 \%)$ & $9(28,1 \%)$ & \\
\hline Posop. infection & & & 0,002 \\
\hline No & $77(67,3 \%)$ & $12(37,5 \%)$ & \\
\hline Yes & $38(32,7 \%)$ & $20(62,5 \%)$ & \\
\hline Preop qual. of life & & & 0,050 \\
\hline Good; light restrict & $64(55,6 \%)$ & $11(33,3 \%)$ & \\
\hline Mod; imp. restrict & $51(44,4 \%)$ & $21(66,7 \%)$ & \\
\hline Death & & & 0,002 \\
\hline No & $102(88,69 \%)$ & $14(43,75 \%)$ & \\
\hline Yes & $13(11,30 \%)$ & $18(56,25 \%)$ & \\
\hline
\end{tabular}

$\mathrm{AP}=$ Associated procedure 
Table 2 - Univariate analysis of study parameters

\begin{tabular}{|c|c|c|c|}
\hline Variable & P Value & Variable & $\mathrm{P}$ Value \\
\hline Height & 0.066 & Weight & 0.193 \\
\hline Body index mass & 0.202 & Angina functional class & 0.087 \\
\hline Angina type & 0.353 & Infarct preop & 0.100 \\
\hline Preop MI time & 0.734 & Preop stroke & 0.614 \\
\hline Heart Failure FC & 0.195 & Dyslipidemia & 0.401 \\
\hline Diabetes & 0.017 & Preop intra-aortic balloon & 0.026 \\
\hline Arterial Hypertension & 0.294 & Cardiac rhythm & 0.101 \\
\hline Preop creatinine & 0.056 & Peripheral atherosclerosis & 0.172 \\
\hline Preop cardiogenic shock & 0.019 & Preop endocarditis & 0.001 \\
\hline Carotid obstruction & 0.865 & Aortic calcification & 0.207 \\
\hline Preop LVEF & 0.323 & Left ventricle morphology & 0.163 \\
\hline $\mathrm{N}^{\circ}$. of damaged arteries & 0.000 & Preop score (Parsonnet) & 0.000 \\
\hline Operative type & 0.163 & Postop MI & 0.178 \\
\hline $\mathrm{CABG}$ and assoc procedure & 0.000 & Extracorporeal uses & 0.000 \\
\hline Extracorporeal time & 0.000 & Aortic clamping & 0.000 \\
\hline $\mathrm{N}^{\circ}$ distal anastomoses & 0.002 & Graft type & 0.000 \\
\hline Postop breathing support & 0.000 & Postop infection & 0.002 \\
\hline Postop low cardiac debit & 0.526 & Postop bleeding & 0.220 \\
\hline Reoperation for bleeding & 0.754 & Postop Heart FC & 0.335 \\
\hline Preop QOL & 0.909 & Postop QOL & 0.050 \\
\hline Postop stroke & 0,000 & Postop creatinine level & 0.018 \\
\hline Hospital length of stay & 0.461 & Hospital mortality & 0.002 \\
\hline
\end{tabular}

When we analyzed postoperative infection with or without systemic repercussions, we observed a higher incidence in Group 2 than in Group 1 patients (37\% versus $32.7 \%, \mathrm{P}=0.002$ ). Infections with systemic repercussions or with mediastinitis occurred in $<2 \%$ of patients in both groups.

Postoperative quality of life was significantly improved for both groups; however, it was greater in Group 1 patients (55.6\% versus $33.3 \%, \mathrm{P}=0.050$ ).

Hospital mortality was greater in Group 2 than in Group 1 patients. We lost 18 patients in Group 2 and 13 in Group 1.

\section{DISCUSSION}

Our findings do not confirm those of Jones et al. ${ }^{1}$ regarding diabetes as a predictor of greater hospital mortality in patients who undergo myocardial revascularization in conjunction with aortic valve replacement. In our study, we observed a greater prevalence of diabetes in the patient group that did not undergo associated procedures $(34.8 \%$ versus $12.5 \%, \mathrm{P}=0.017$ ).

Although we used the preoperative Parsonnet risk score and not the EuroSCORE, we agree with Biancari et al. ${ }^{7}$ that the Parsonnet score is the most relevant predictor of immediate clinical outcomes after CABG. In our study, the risk score for Group 2 patients was higher than that for Group $1(33 \pm 8.33$ versus $24.12 \pm 8.39, \mathrm{P}<0.001)$ and had a significant impact on hospital mortality $(\mathrm{P}=0.002)$.

In our study, a female gender did not directly influence hospital mortality. However, the percentage of females was greater in Group 2 (46.9\% versus 39.5\%, $\mathrm{P}=0.456$ ).

Our findings may corroborate those of Doenst et al, ${ }^{11}$ who indicated that female sex is a predictor of higher risk for postoperative stroke in patients who undergo concomitant coronary artery and valve procedures. In our study, we had a larger percentage of female patients in Group 2 than in Group 1 (46.9\% versus 39.5\%-P=0.456), and Group 2 had a greater occurrence of postoperative stroke $(21.9 \%$ versus $3.5 \%, \mathrm{P}<0.001)$.

The present study supports the results of Toumpoulis et $\mathrm{al},{ }^{12}$ who found respiratory insufficiency and postoperative infection to be isolated risk factors for late mortality in both sexes. In our study, postoperative breathing support and infection contributed to increased hospital mortality. The need for breathing support was greater in Group 2 (53.2\% versus $19.1 \%, \mathrm{P}<0.001$ ), which had a higher hospital 
mortality. Infection was also greater in Group 2 (37\% versus $32.7 \%, \mathrm{P}=0.002$ ).

Our findings concur with those of Mistiaen et al. ${ }^{13}$ who identified preoperative renal dysfunction as an isolated risk factor for mortality. Preoperative renal dysfunction was greater in Group 2 (3.1\% versus $1.7 \%, \mathrm{P}=0.056)$, but it did not influence hospital mortality in our study. We found a greater prevalence of postoperative renal dysfunction in Group 2 patients $(28.1 \%$ versus $11.3 \%, \mathrm{P}=0.018)$; this was related to the greater hospital mortality in that group.

Our findings support those of Mistiaen et al, ${ }^{13}$ who identified a history of treated endocarditis and left ventricular dysfunction as preoperative risk factors. For the treated endocarditis, a larger prevalence existed in Group $2(15.6 \%$ versus $1.7 \%, \mathrm{P}=0.001$ ); this was significant because of the greater hospital mortality found in this group. Decreased left ventricular function was related to two variables identified as factors of preoperative risk: preoperative cardiogenic shock and preoperative need for the intra-aortic balloon pump. For cardiogenic shock, a greater prevalence was found in Group 2 patients (22.6\% versus $7.8 \%, \mathrm{P}=0.019)$. There was a much greater prevalence of the use of the intra-aortic balloon pump in Group 2 than in Group 1 patients (18.8\% versus $6.1 \%$, $\mathrm{P}=0.026$ ).

Our findings do not agree with those of Jones et al. ${ }^{1}$ who found that the use of a vein graft for the interventricular anterior branch of the left coronary artery in revascularization combined with aortic valve substitution improved survival. In our study, more patients who underwent associated procedures used vein grafts ( $76.7 \%$ group 2 versus $31.5 \%$ group 1), and this was linked to the greater mortality observed in Group 2 patients $(\mathrm{P}=0.002)$. However, our findings agree with the identification of the number of grafts performed as an inverse cause of reduced survival. We found that a smaller number of grafts were completed in Group 2 than in Group 1 ( $2.0 \pm 0.80$ versus $2.57 \pm 0.89, \mathrm{P}=0.002)$, with Group 2 having a higher hospital mortality.

The findings of the present study agree with those of Jensen et al. ${ }^{5}$ who found that CABG improves the quality of life regardless of whether it is performed with or without extracorporeal circulation. In our study, we confirmed improved quality of life in the postoperative period in both groups; however, quality of life scores were better in Group 1 than in Group 2 patients (55.6\% versus 33.3\%, $\mathrm{P}=0.050$ ).

We did not confirm the findings of Rankin et al, ${ }^{10}$ who showed that coronary artery disease was a risk factor for concomitant revascularization and valve surgery (odds ratio=1.58). In our study, the patient group with higher mortality had less severe coronary artery disease $(2.06 \pm 0.71$ versus $2.59 \pm 0.67, \mathrm{P}<0.001)$.

Our findings confirm those of Reston et al. ${ }^{14}$ who reported that the frequency of renal dysfunction, stroke, and hospital mortality was less in patients operated on without extracorporeal circulation. In our study, in 98 of the 115 patients operated on without extracorporeal circulation, we found a reduced prevalence of postoperative renal dysfunction (11.3\% versus $28.1 \%, \mathrm{P}=0.018)$ and of stroke (3.5\% versus $21.9 \%, \mathrm{P}<0.001)$ in Group 1 when compared to Group 2 that was related to the lower hospital mortality in that group $(\mathrm{P}=0.002)$.

Our discoveries are in accord with those of Mack et al, ${ }^{15}$ who found extracorporeal circulation to be an independent predictor of increased hospital mortality $(\mathrm{P}<0.001)$. In our study, the patients in the group that received associated procedures all needed extracorporeal circulation $(100 \%$ versus $42.6 \%, \mathrm{P}<0.001)$; this resulted in the greater mortality observed in that group $(\mathrm{P}=0.002)$.

\section{CONCLUSION}

The performance of procedures associated with surgical myocardial revascularization in octogenarian patients produced a $45 \%$ increase in the risk of hospital mortality. The risk factors that contributed most to the deaths were: previous endocarditis, preoperative cardiogenic shock, hospital stay, postoperative creatinine levels, use of extracorporeal circulation, time of extracorporeal circulation, and need for prolonged respiratory support in the postoperative period.

\section{REFERENCES}

1. Jones JM, Loveli D, Cran GW, MacGawan SW. Impact of coronary artery bypass grafting on survival after valve replacement. Interact Cardiovasc Thorac Surg. 2006;5:327-30.

2. Nwakanma L, Poonyagariyagorn HK, Bello R, Khoynezhad A, Smego D, Plestis KA. Early and late results of combined carotid endarterectomy and coronary artery bypass versus isolated coronary artery bypass. Interact CardioVasc Thorac Surg. 2006;5:159-65.
3. Woo YJ, Grand TJ, Liao GP, Panlilio CM. Off-pump revascularization for significant left ventricular dysfunction. Asian Cardiovasc Thorac Ann. 2006;14:306-9.

4. Sirivella S, Gielchinsky I. Clinical outcomes of surgery of mitral valve regurgitation and coronary bypass grafting. Interact CardioVasc Thorac Surg. 2006;5:392-7. 
5. Jensen BO, Hughes P, Rasmussen LS, Pedersen PU, Steinbruchel DA. Health related quality of life following off-pump versus on-pump coronary artery bypass grafting in elderly moderate to high risk patients: the randomized trial. Eur J Cardiothorac Surg. 2006;30:294-9.

6. Onorati F, Cristodoro L, Bilotta M, Impiombato B, Pezzo F, Mastroroberto $\mathrm{P}$, et al. ntraaortic balloon pumping during cardioplegic arrest preserves lung function in patients with chronic obstructive pulmonary disease. Ann Thorac Surg. 2006;82:35-43.

7. Biancari F, Kangasniemi OP, Luukkonen J, Vuorisalo S, Satta J, Pokela $\mathrm{R}$, et al. EuroSCORE predicts immediate and late outcome after coronary artery bypass surgery. Ann Thorac Surg. 2006;82:57-61.

8. Reddy SLC, Grayson AD, Oo AY, Pullan MD, Poonacha T, Fabri BM. Does off-pump surgery offer benefit in high respiratory risk patients? A respiratory risk stratified analysis in a propensity-matched cohort. Eur J Cardiothorac Surg. 2006;30:126-31.

9. Rocha-e-Silva R, Santos TS, Rochite CE, Rocha-Filho JA, Mansur AP, Fabri J Jr, et al. Elective vs non-elective radial artery grafts: comparing midterm results through 64-Slice computed tomography._Clinics. 2007;62:725-30.
10. Rankin JS, Hammill BG, Ferguson TB Jr, Glower DD, O’Brien SM, DeLong ER,et al. Determinants of operative mortality in valvular heart surgery. J Thorac Cardiovasc Surg. 2006;131:547-57.

11. Doenst T, Ivanov J, Borger MA, David YOU, Brister SJ. Sex specific long-term outcomes after combined valve and coronary artery surgery. Ann Thorac Surg. 2006;81:1632-6.

12. Toumpoulis IK, Anagnostopoulos CE, Balaram SK, Rokkas CK, Swistel DG, Ashton RC Jr, et al. Assessment of independent predictors for longterm mortality between women and men after coronary artery bypass grafting: Are women different from men? J Thorac Cardiovasc Surg. 2006;131:343-51.

13. Mistiaen W, Van Cauwelaert P, Muylaert P, Wuyts F, Harrisson F, Bortier H. Risk factors and survival after aortic valve replacement in octogenarians. J Heart Valve Dis. 2004;13:538-44.

14. Reston JT, Tregear SJ, Turkelson CM. Meta-analysis of short-term and mid-term outcomes following off-pump coronary artery bypass grafting. Ann Thorac Surg. 2003;76:1510-5.

15. Mack MJ, Pfister THE, Bachand D, Emery R, Magee MJ, Connolly $\mathrm{M}$, et al. Comparison of coronary bypass surgery with and without cardiopulmonary bypass in patients with multivessel disease. J Thorac Cardiovasc Surg. 2004;127:167-73. 